\title{
Urinary Schistosomiasis in an Elderly Patient: The Ultrasonographic Findings and Case Report
}

\author{
Sule MB ${ }^{1 *}$, Umar $\mathrm{AU}^{2}$, Gele $\mathrm{IH}^{3}$, Yisa $\mathrm{CB}^{3}$, Bilyaminu $\mathrm{U}^{3}$, Gidado $\mathrm{S}^{3}$, Sarki $\mathrm{HA}^{3}$, Aliyu $\mathrm{AZ}^{3}$ \\ ${ }^{1}$ Radiology Department, Usmanu Danfodiyo University, Sokoto \\ ${ }^{2}$ Radiology Department, Gombe State University, Gombe \\ ${ }^{3}$ Radiology Department, Usmanu Danfodiyo University Teaching Hospital, Sokoto \\ *Corresponding author: SULE Muhammad Baba, Department of Radiology, Usmanu Danfodiyo University, Sokoto. \\ Received date: March 27, 2021 ; Accepted date: April 14, 2021; Published date: April 26,2021
}

Citation: Sule MB, Umar AU, Gele IH, Yisa CB, Bilyaminu U, et al. (2021). Urinary Schistosomiasis in an Elderly Patient: The Ultrasonographic Findings and Case Report. J Clinical Research and Reports, 7(4); DOI:10.31579/2690-1919/159

Copyright: (c) 2021 SULE Muhammad Baba, This is an open access article distributed under the Creative Commons Attribution License, which permits unrestricted use, distribution, and reproduction in any medium, provided the original work is properly cited.

\begin{abstract}
Urinary schistosomiasis (US) causes chronic ill health and caused by the blood fluke Schistosoma haematobium. This disease is endemic in Africa and eastern Mediterranean countries, and has a predilection for the male gender.

This is a 64-year-old farmer (swampy farming and fishing) for more than forty years, that was referred from a peripheral health care centre for abdominal and pelvic ultrasonography on account of abdominal pain and discomfort, bilateral loin pain, dysuria, and terminal hematuria for close to a year duration of onset.

The ultrasonography demonstrated bladder wall thickening, mucosal thickening and polypoid proliferation in to the bladder lumen, irregular echogenic crust in the bladder base, suspended mobile echoes in urine most likely from hematoma and/or cystitis, there is associated mild-moderate biliterate dilatation of the pelvi-calyceal systems and ureters(hydroureteronephrosis). The remaining abdominal and pelvic organs appeared normal.

Urinary parasitology demonstrated the ova of Schistosoma haematobium confirming the diagnosis of urinary schistosomiasis.

We report the ultrasonographic features of urinary schistosomiasis because of its peculiar presentation and to emphasize importance of ultrasound in its assessment.

Keywords: ultrasonography; schistosomiasis; urinary bladder; hydroureteronephrosis; pelvi-calyceal; praziquantel; parasitology
\end{abstract}

\section{Introduction}

Urinary schistosomiasis is mainly caused by Schistosoma haematobium especially in endemic areas, the sites of predilection are the bladder, lower ureters, urethra, seminal vesicles, cervix, and vagina [1].

Following deposition of the ova from Schistosoma at predilection sites, this initiates granuloma formation and coalesce to form pseudotubercles appearing as seed-like bodies with circumferential zone of hyperemia; seen in early and active disease. The late presentation is the sandy patch; these are calcified ova beneath the atrophic mucosa appearing like sand giving the mucosa a ground-glass appearance $[1,2]$.

The world Health Organization (WHO), in 1996, estimated that about 200 million individuals were affected by schistosomiasis worldwide, and most are rural dwellers, about 20 million of these were severely affected by the disease and another 120 million were symptomatic with the disease $[3,4]$.

Schistosomiasis is endemic in sub-Saharan African most especially Nigeria, the burden of the disease is estimated at about 29 million cases, with varying cases of both urinary and intestinal cases across the country, though the cases of urinary infection appear prevalent $[5,6]$.

Schistosomiasis has predilection for the male gender most likely occupationally inclined, following exposure to infected water from swimming, fishing and other agricultural activities. The prevalence and severity of the disease appears more in children and adolescent $[7,8]$.

Schistosomiasis often present with varying features especially among the male gender, these are loin pain, terminal hematuria, hemospermia, dysuria, lower abdominal pain $[1,3,9]$.

The diagnosis of schistosomiasis is made by detection of the parasite ova in stools, urine, and biopsy specimens from affected organs, or presence of antibodies to the different stages of the parasite or antigens circulating in the body fluids by serologic techniques $[10,11]$.

Radiological imaging also plays role in the diagnosis of urinary schistosomiasis, these are basically ultrasonography, Doppler studies, plain radiography, computed tomographic scan (CT), cystoscopy and magnetic imaging resonance (MRI) [1,10,12]. 
The treatment of urinary schistosomiasis is widely done by administration of oral praziquantel in a dose of about $40 \mathrm{mg}$ per body kilogram as a single dose, other regimen which include metrifonate and artemisinin have been also used, though praziquantel happens to be widely accepted and most efficacious $[1,13]$.

\section{Case Report}

This is a 64-year-old farmer (swampy farming and fishing) for more than forty years, that was referred from a peripheral health care centre for abdominal and pelvic ultrasonography on account of abdominal pain and discomfort, bilateral loin pain, dysuria, and terminal hematuria for close to a year duration of onset.

The patient is conscious and alert and well oriented, not pale, anicteric, acyanosed, no finger clubbing and not in painful distress and no pedal edema or swelling of any body part currently.

The patient had a blood pressure of about $120 / 70 \mathrm{mmHg}$, pulse rate was 72 beats per minute and a respiratory rate of about 12 cycles per minute.

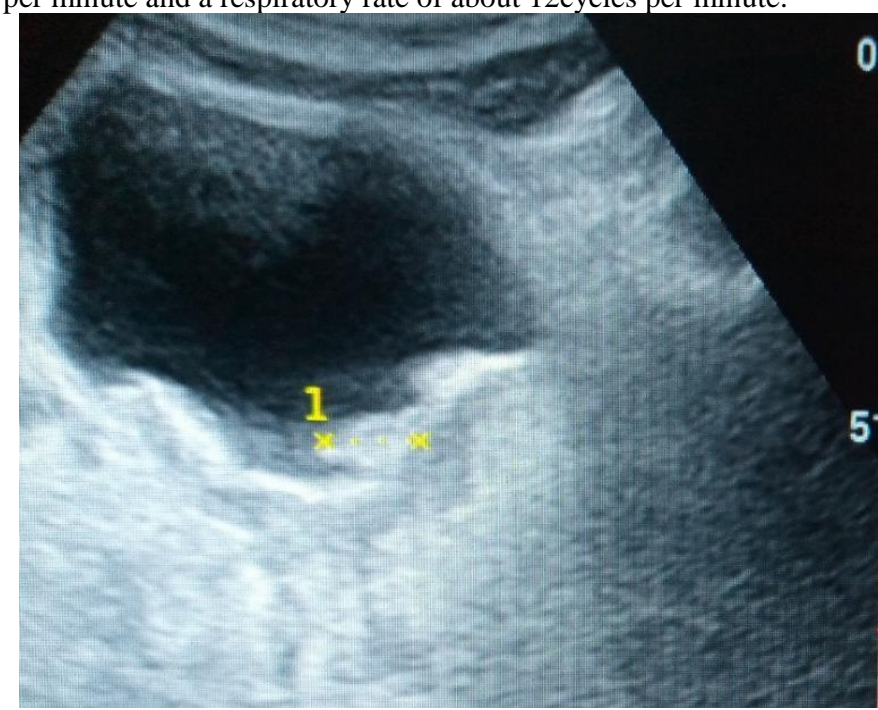

The blood electrolytes were normal, blood urea was also normal (12milligram per deciliter) and blood creatinine level was also normal (1.1milligram per deciliter of blood), the packed cell volume was about $38 \%$ and the erythrocyte sedimentation rate was $7 \mathrm{~mm} / \mathrm{hr}$. the white blood cell count was elevated and about 13500 white blood cells per microliter.

Urine analysis demonstrated pus cells, and blood cells, no protein nor glucose was demonstrated in the urine sample.

The ultrasonography demonstrated a bladder appearing contracted with diminished capacity, bladder wall thickening of about $9.6 \mathrm{~mm}$, mucosal thickening and polypoid proliferation (measuring about $12.1 \mathrm{~mm}$ in diameter) in to the bladder lumen, irregular echogenic crust in the bladder base, suspended mobile echoes in urine most likely from hematoma and/or cystitis (all in figure 1), there is associated mild-moderate biliterate dilatation of the pelvi-calyceal systems (figure 2) and ureters; the hydroureteronephrosis. The remaining abdominal and pelvic organs appeared normal.

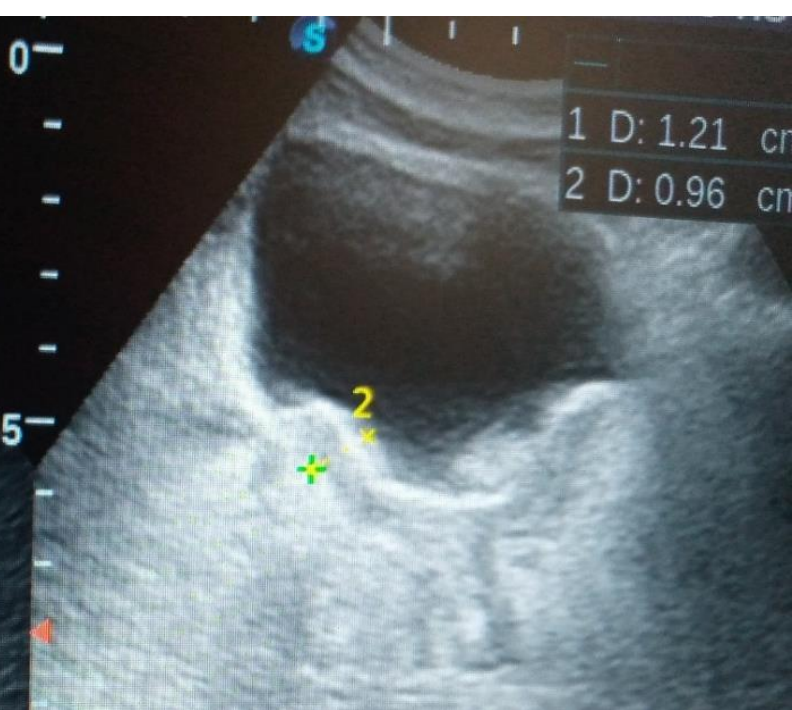

Figure 1: Pelvic sonograms, the left image demonstrates a contracted bladder with diminished capacity, bladder wall thickening of about 0.96cm and irregularity more in the base, echogenic crust in the base with two polypoid mucosal proliferation measuring about $1.21 \mathrm{~cm}$ most likely schistosomes. The right image also demonstrates similar findings.

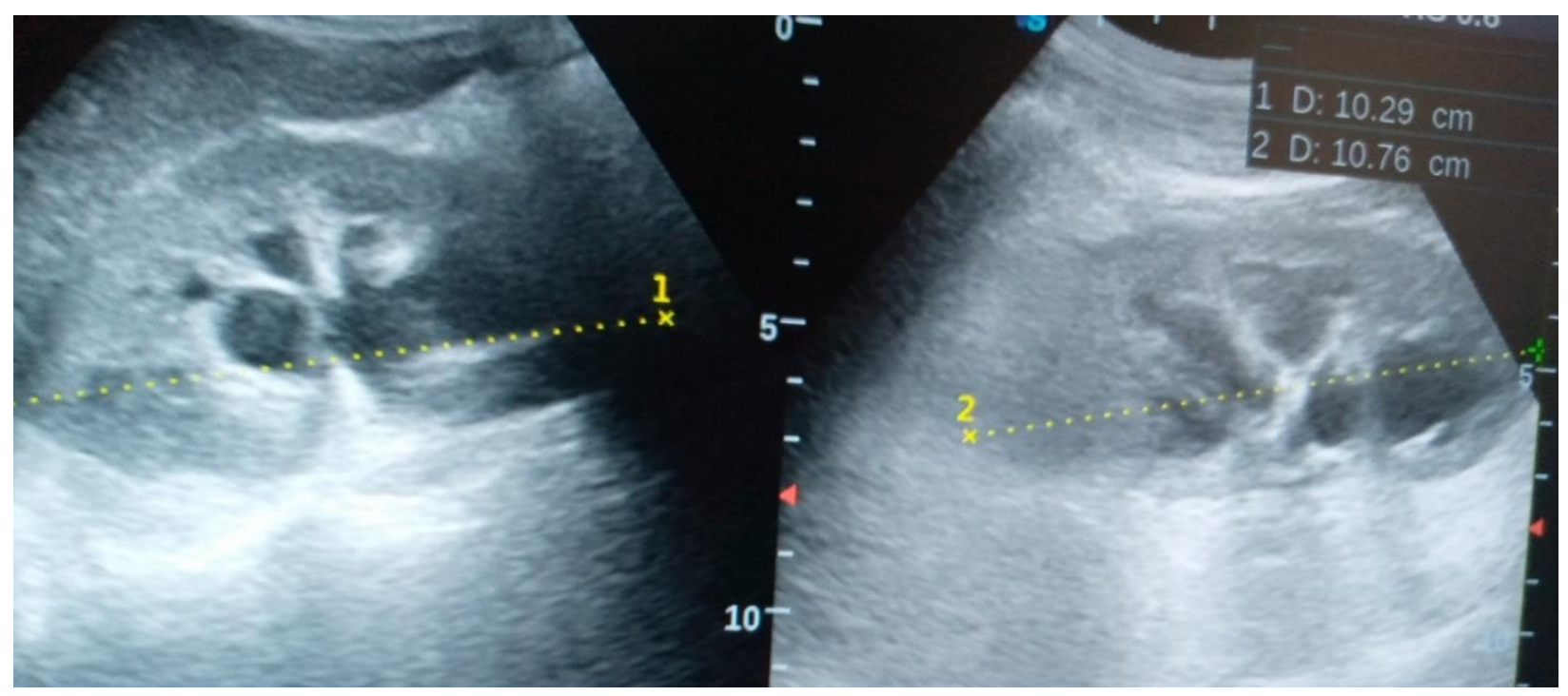

Figure 2: Renal sonograms, both left and right images demonstrates dilatation of the calyceal moieties on the left and right kidneys respectively. The kidneys measure about $10.76 \mathrm{~cm}$ and $10.29 \mathrm{~cm}$ on the left and right respectively. 
Urinary parasitology demonstrated the ova of Schistosoma haematobium confirming the diagnosis of urinary schistosomiasis.

The patient was administered with oral praziquantel in a dose of $40 \mathrm{mb} /$ body kilogram, he had a first course to repeat the parasitology after two-weeks, he was also advised on good personal health and hygienic practices, and to come for a follow-up visit in two-weeks.

\section{Discussion}

Urinary schistosomiasis is a tropical infection caused by Schistosoma haematobium, regarded as part of the neglected Tropical diseases with high incidence across African continent affecting more than 200 million people [14]. The case under review is of the African descent, living in an African country with Schistosoma Haematobium detected in his urine sample, thereby conforming to this literature.

Schistosomiasis has predilection for the male gender most likely occupationally inclined, following exposure to infected water from swimming, fishing and other agricultural activities. The prevalence and severity of the disease appears more in children and adolescent $[7,8]$. The case under review is a male, a fisherman and farms in a swampy land for almost forty years, thereby conforming to these literatures.

Schistosomiasis is endemic in sub-Saharan African most especially Nigeria, the burden of the disease is estimated at about 29 million cases, with varying cases of both urinary and intestinal cases across the country, though the cases of urinary infection appear prevalent $[5,6]$. The index case lives in Nigeria, a sub-Saharan country with features of urinary schistosomiasis, thereby conforming to these literatures.

Schistosomiasis often present with varying features especially among the male gender, these are loin pain, terminal hematuria, hemospermia, dysuria, lower abdominal pain [1,3,9]. The case under review also presented with dysuria, hematuria, lower abdominal pain and discomfort. Thereby conforming to these literatures.

Patients with schistosomiasis often present with secondary bacterial infection, in adults, hematuria may disappear, with evolvement of fibrosis, calcification, hydroureteronephrosis, eventual renal failure, with chronicity squamous cell carcinoma may also occur $[12,14]$. The index case had hematuria, echogenic crust most likely calcification, fibrosis, hydroureteronephrosis, but no evidence of renal failure and malignant transformation as at the time of this report.

Radiological imaging also plays role in the diagnosis of urinary schistosomiasis, these are basically ultrasonography, Doppler studies, plain radiography, computed tomographic scan (CT), cystoscopy and magnetic imaging resonance (MRI) $[1,10,12]$. The index case had ultrasonography with Doppler interrogation, these demonstrated varying changes in the bladder and urinary tracts, the Doppler showed increased vascularity in the bladder wall/mucosa. These agrees with the above literatures.

Ultrasonography is vital in assessing cases of urinary schistosomiasis in detecting the disease and the severity, this demonstrates varying degree of bladder and ureteric and renal affectation of schistosomiasis most commonly wall thickening with hydroureteronephrosis [15-18]. The patient had ultrasonography, this demonstrated a bladder that appear contracted with circumferential wall thickening more in the base, mucosal thickening and protrusion in to the lumen, presence of irregular echogenic crust in the base with associated suspended mobile echoes in urine. Bilateral mild-moderate hydroureteronephrosis was also demonstrated in this patient. Thereby agreeing to these literatures.

The treatment of urinary schistosomiasis is widely done by administration of oral praziquantel in a dose of about $40 \mathrm{mg}$ per body kilogram as a single dose, other regimen which include metrifonate and artemisinin have been also used, though praziquantel happens to be widely accepted and most efficacious [1,13]. The case under review had a course of praziquantel in a dose of $40 \mathrm{mg} / \mathrm{kg}$, thereby conforming to these literatures.

\section{Conclusion}

Schistosomiasis is endemic in Africa, and most times occupational related, individuals with high risk should be monitored adequately by urine parasitology and ultrasonography to prevent occurrence of schistosomiasis among these subjects thereby reducing the morbidity and complication of malignant transformation amongst them.

\section{References}

1. Tzanetou K, Adamis G, Andipa E, Zorzos C, Ntoumas K, Armenis K, et al 2007. Urinary Tract Schistosoma haematobium Infection: A Case Report. J Travel Med. 14:334337.

2. Ghoneim MA, 2002. Bilharziasis of the genitourinary tract. BJU Int. 89:22-30.

3. Shebel HM, Elsayes KM, Abou EL Atta HM, Elguindy YM, El-Diasty TA, 2012. Genitourinary Schistosomiasis: Life Cycle and Radiologic-Pathologic Findings. RadioGraphics. 32:10311047.

4. Ross AG, Bartley PB, Sleigh AC 2002. Schistosomiasis. N Engl J Med. 346:1212-1220.

5. Adenowo AF, Oyinloye BE, Ogunyinka BI, Kappo AP, 2015. Impact of human schistosomiasis in sub-Saharan Africa. Brazillian Journal of Infectious Diseases. 19:196-205.

6. Houmsou RS, Panda SM, Elkanah SO. Cross-sectional study and spatial distribution of schistosomiasis among children in North-Eastern Nigeria. Asian Pacific Journal of Tropical Biomedicine. 2016; 6:477-484.

7. Mwanakasale V, Siziya S, Mwansa J, Koukounari A, Fenwick A, 2009. Impact of Iron Supplementation on Schistosomiasis Control in Zambian School Children in a Highly Endemic Area. Malawi Med J. 21:12-18.

8. Faruk S, Azeez AO, Isa AS, Zubairu I, 2011. Urinary Schistosomiasis in the Danjarima Community in Kano, Nigeria. The Journal of Infection in Developing Countries. 3:452-457.

9. Poggensee G, Sahebali S, Van Marck E, 2001. Diagnosis of genital cervical schistosomiasis: comparison of cytological, histopathological and parasitological examination. Am J Trop Med Hyg. 65:233-236.

10. Olveda DU, Olveda RM, Lam AK, Chau TNP, Li Y, Gisparil II AD, et al. 2014. Utility of Diagnostic Imaging in the Diagnosis and Management of Schistosomiasis. Clin Microbial. $3: 2-7$.

11. Feldmeier H, Poggensee G, 1993. Diagnostic techniques in schistosomiasis control. A review. Acta Trop. 52:205-220.

12. Sah VK, Wang L, Min X, Rival R, Feng Z, Ke Z, et al. 2015. Human Schistosomiasis: A diagnostic imaging focused review of a neglected disease. Radiol Infec Dis. 2:150-157.

13. Danso-Appiah A, Garner P, Olliaro PL, Utzinger J, 2009. Treatment of urinary schistosomiasis: methodological issues and research needs identified through a Cochrane systematic review. Parasitology. 136:1837-1849.

14. Hassan SI, Talaat M, El Attar GM, 1994. Evaluation of Urinalysis Reagent Strips versus Microscopical Examination of Urine for Schistosoma haematobium. J Egypt Soc Parasitol. 24:603-609.

15. Feldmeier H, Poggensee G, 1993. Diagnostic techniques in schistosomiasis control. A review. Acta Trop. 52:205-220.

16. Ferrara D, Esposito F, Di Serafino M, Gullotto C, Baglioni A, Martinelli L, et al. 2018. Sonographic early findings in a case of bladder schistosomiasis. J Ultrasound. 21:259-263. 
17. Richter J, Hatz C, Capangne G, Bergquist N, Jenkins J, 2000. Geneva: World Health Organization.
18. Skelly P, 2013. The use of imaging to detect schistosomes and diagnose schistosomiasis. Parasite Immmunol. 35:295-301.
This work is licensed under Creative Commons Attribution 4.0 License

\section{To Submit Your Article Click Here: Submit Manuscript}

DOI: $10.31579 / 2690-1919 / 159$
Ready to submit your research? Choose Auctores and benefit from:

* fast, convenient online submission

* rigorous peer review by experienced research in your field

* rapid publication on acceptance

* authors retain copyrights

* unique DOI for all articles

* immediate, unrestricted online access

At Auctores, research is always in progress.

Learn more www.auctoresonline.org/journals/journal-of-clinicalresearch-and-reports 